Revista Universo Contábil, ISSN 1809-3337

FURB, v. 5, n. 2, p. 24-38, abr./jun., 2009

doi:10.4270/ruc.2009211

Disponível em www.furb.br/universocontabil

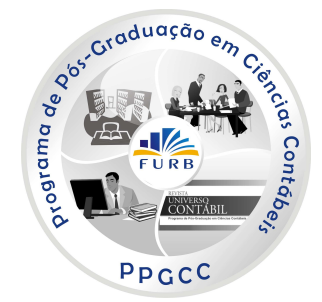

\title{
DESEMPENHO DO ÍNDICE DE SUSTENTABILIDADE EMPRESARIAL (ISE) DA BOLSA DE VALORES DE SÃO PAULO*
}

\section{MANAGERIAL SUSTAINABILITY INDEX (ISE) PERFORMANCE OF SÃO PAULO STOCK EXCHANGE}

\author{
Márcia Reis Machado \\ Doutoranda em Ciências Contábeis na FEA/USP \\ Professora da Universidade Federal da Paraíba- UFPB \\ Endereço: Departamento de Finanças e Contabilidade. \\ Cidade Universitária - Campus I - Castelo Branco \\ CEP: 58059-900 - João Pessoa/PB - Brasil \\ E-mail: marciareism@hotmail.com \\ Telefone: (83) 2167486 \\ Márcio André Veras Machado \\ Doutorando em Administração na UnB \\ Professor da Universidade Federal da Paraíba- UFBB \\ Endereço: Departamento de Administração \\ Cidade Universitária - Campus I - Castelo Branco \\ CEP: 58059-900 - João Pessoa/PB - Brasil \\ E-mail: mavmachado@hotmail.com \\ Telefone: (85) 32167492
}

Luiz João Corrar

Doutor em Controladoria e Contabilidade pela FEA/USP

Professor do Departamento de Contabilidade e Atuária da FEA/USP Endereço: Av. Prof. Luciano Gualberto, 908 - FEA 3 - Butantã CEP: 05508-900 - São Paulo/SP - Brasil

E-mail: ljcorrar@usp.br

Telefone: (11) 3091-5820

\section{RESUMO}

Muitos são os motivos que levam empresas a aderir ao movimento pelo social, razões essas que nem sempre são assumidas publicamente. Diante dessa preocupação com a

\footnotetext{
Artigo recebido em 30.08.2008. Revisado por pares em 27.10.2008. Reformulado em 02.12.2008. Recomendado em 15.12.2008 por Ilse Maria Beuren (Editora). Publicado em 30.06.2009. Organização responsável pelo periódico: FURB.
} 
responsabilidade social e a sustentabilidade empresarial, medidas foram desenvolvidas para avaliar a valorização das ações de empresas que investem em responsabilidade social e ambiental, a exemplo do Índice de Sustentabilidade Dow Jones, Fundo Ethical e, recentemente, o Índice de Sustentabilidade Empresarial - ISE da Bolsa de Valores de São Paulo. Fundamentado na teoria dos stakeholders e na hipótese de eficiência de mercado, o presente estudo tem por objetivo averiguar se a rentabilidade média do Índice de Sustentabilidade Empresarial (ISE) é estatisticamente igual à rentabilidade dos demais índices da BOVESPA, no período de dezembro de 2005 a novembro 2007. Para atingir ao objetivo proposto, fez-se uso de testes paramétrico e não-paramétrico, concluindo não haver diferença significativa entre o ISE e os demais índices da BOVESPA. O resultado apresentado não pode levar à conclusão de que investimentos socialmente responsáveis apresentam o mesmo retorno de investimentos que não adotam postura idêntica, mas que o retorno médio dos índices é semelhante, uma vez que um número relevante de empresas compõe simultaneamente mais de um índice.

Palavras-chave: Índice de Sustentabilidade Empresarial. Responsabilidade Social. Investimentos Sociais.

\section{ABSTRACT}

Many are the reasons that lead companies to adhere to social movements, reasons that are not always assumed openly. Due to the concern with social responsibility and managerial sustainability, measures were developed to evaluate the stock prices of companies that invest in social and environmental responsibility, as the Dow Jones Sustainability, Ethical Fund and, recently, the Managerial Sustainability Index - ISE of the stock exchange of São Paulo. Based on the stakeholders theory and on the market efficiency hypothesis, the present study has as purpose discover whether the Managerial Sustainability Index (ISE) average profitability is similar to the profitability of other BOVESPA indexes, during the period from December of 2005 to November 2007. To reach the proposed objective, parametric and nonparametric tests were conducted, concluding that there are no significant differences between ISE and other BOVESPA indexes. The presented result cannot take to the conclusion that socially responsible investments present the same return as investments that don't adopt the same posture; however, the return average of the indexes is similar, once a relevant number of companies simultaneously compose more than one index.

Keywords: Managerial Sustainability Index. Social Responsibility. Social Investments.

\section{INTRODUÇÃO}

É crescente a quantidade de estudos relacionados à responsabilidade social e ambiental, bem como o interesse da mídia, de empresários e governos. A responsabilidade social envolve uma gestão empresarial, diz respeito à maneira como as empresas agem, sua postura ética e preocupação social e ambiental.

Muitos são os incentivos existentes para a divulgação da responsabilidade social, a exemplo de prêmios e selos concedidos pelos Estados e órgãos não governamentais para empresas que demonstram qualidade e transparências em suas ações sociais, principalmente por meio da divulgação de Balanço Ambiental e Social de qualidade.

Inúmeros são os motivos que levam as empresas a aderir ao movimento pelo social, razões essas que nem sempre são assumidas publicamente. Diante dessa preocupação com a responsabilidade social e a sustentabilidade empresarial, medidas foram desenvolvidas para 
avaliar a valorização das ações de empresas que investem em responsabilidade social e ambiental.

Em 1999, foi criado, nos EUA, o Dow Jones Sustainability Index (DJSI - Índice de Sustentabilidade Dow Jones), primeiro índice a avaliar o desempenho financeiro das empresas líderes em sustentabilidade. No Brasil, o primeiro fundo de investimento composto por empresas reconhecidas por desenvolverem boas práticas de responsabilidade social, ambiental e corporativa foi o Fundo Ethical, criado em 2001 pelo ABN AMRO. Em 2005, a Bovespa lançou o Índice de Sustentabilidade Empresarial (ISE), indicador composto de ações emitidas por empresas que apresentam alto grau de comprometimento com sustentabilidade e responsabilidade social.

Com base no exposto, questiona-se: Como tem se comportado a rentabilidade média da carteira ISE em relação às demais carteiras da BOVESPA? Assim, o objetivo geral da pesquisa consiste em averiguar se a rentabilidade média do Índice de Sustentabilidade Empresarial (ISE) é estatisticamente igual à rentabilidade dos demais índices da BOVESPA, dentro do período de dezembro de 2005 a novembro 2007.

Este artigo está estruturado em cinco partes, incluindo a introdução. A seguir, apresenta-se a revisão da literatura, a qual contempla os aspectos sobre sustentabilidade empresarial e temas relacionados e a relação entre investimentos socialmente responsáveis e o desempenho financeiro. Na terceira parte, define-se o proceder metodológico, que por sua vez contempla a abordagem metodológica e a técnica da pesquisa. Na quarta parte, apresentam-se os resultados da pesquisa. Na quinta parte, a conclusão.

\section{REFERENCIAL TEÓRICO}

\subsection{Sustentabilidade empresarial e temas relacionados}

Sustentabilidade empresarial, responsabilidade social empresarial, ética empresarial, cidadania corporativa, performance social corporativa, Triple Bottom Line são alguns dos termos utilizados para destacar a responsabilidade das empresas, além dos objetivos puramente financeiros.

O conceito de sustentabilidade foi inicialmente utilizado nas disciplinas de Economia Ambiental e Ética Empresarial (BARBOSA, 2007), caracterizando-se como um termo interdisciplinar, uma vez que é usado em várias áreas do conhecimento. A sustentabilidade pode ser entendida como uma questão de se estabelecer distribuição igualitária de bem-estar associado aos recursos naturais nas dimensões inter e intra-temporal (SOLOW, 1991 apud MASULLO, 2004).

A dimensão inter-temporal diz respeito aos esforços para permitir que gerações futuras tenham os mesmos recursos e qualidade semelhante à atual; a dimensão intra-temporal procura estabelecer que os custos da degradação ambiental sejam pagos por quem os geram, compensando ou evitando a perda de bem-estar dos usuários não beneficiados por este capital natural (SEROA DA MOTTA, 1998 apud MASULLO, 2004).

Segundo Byrch et al. (2007), a definição mais utilizada na literatura consultada é a de desenvolvimento sustentável do documento A/42/427, conhecido por Relatório Brundtland, publicado pela Comissão Mundial de Meio Ambiente e Desenvolvimento, em 1987, que define o desenvolvimento sustentável como o desenvolvimento que satisfaz às necessidades da geração presente sem comprometer a capacidade de gerações futuras em satisfazer suas próprias necessidades.

O relatório Brundtland enfatiza dois conceitos chaves: necessidade, especialmente de países pobres, para os quais deve ser dada prioridade, e limitações, que devem ser impostas 
pelo estado e organizações sociais para evitar que a degradação ambiental impossibilite atender às necessidades de gerações futuras (BYRCH et al., 2007).

São componentes fundamentais para o desenvolvimento sustentável: crescimento econômico, proteção ao meio-ambiente e igualdade social. Esses fundamentos, juntamente com a mudança do paradigma das empresas, que tinham como único foco o lucro, deram origem ao Triple Bottom Line (BARBOSA, 2007).

A idéia base do Triple Bottom Line é de que o sucesso e saúde de uma empresa não devem ser avaliados somente por medidas financeiras tradicionais, mas também por sua ética, responsabilidade social, e seu desempenho ambiental (NORMAN; MACDONALD, 2003).

Responsabilidade social corporativa é outro conceito relacionado e por vezes confundido com sustentabilidade corporativa (BARBOSA, 2007). De acordo com o Business for Social Responsibility, não existe uma definição única para responsabilidade social corporativa, "mas, de forma ampla, ela refere-se a decisões de negócios tomadas com base em valores éticos que incorporam as dimensões legais, o respeito pelas pessoas, pelas comunidades e pelo meio ambiente" (MACHADO FILHO; ZYLBERSZTAJN, 2004).

\footnotetext{
A responsabilidade social das empresas tem como principal característica a coerência ética nas práticas e relações com seus diversos públicos, contribuindo para o desenvolvimento contínuo das pessoas, das comunidades e dos relacionamentos entre si e com o meio ambiente. Ao adicionar às suas competências básicas a conduta ética e socialmente responsável, as empresas conquistam o respeito das pessoas e das comunidades atingidas por suas atividades, o engajamento de seus colaboradores e a preferência dos consumidores (INSTITUTO ETHOS, 2001).
}

Para Barbosa (2007), o conceito de cidadania corporativa refere-se à empresa como cidadão corporativo, que tem responsabilidade e deve agir de acordo com a demanda social advinda dessa responsabilidade.

\begin{abstract}
Responsabilidade social corporativa e cidadania empresarial - apresentam-se em processo de maturação de diversas tendências de abordagem, requerendo, para sua construção teórica e aplicação prática, o desenvolvimento de seus respectivos constructos para a sua definição, mensuração e validação. Neste sentido, a abstração ainda presente em ambos os conceitos deve dar lugar à construção de indicadores associados às variáveis relacionadas às respectivas dimensões e relações da empresa com seus diversos grupos de stakeholders (ASHLEY; COUTINHO; TOMEI, 2000, p. 12).
\end{abstract}

Sendo considerada a empresa como uma pessoa artificial, essa possui atribuições éticas. A dimensão ética da sociedade é complementar às suas dimensões econômica e legal e pode ser vista sob dois enfoques: dos stockholders e dos stakeholders. Neste contexto, são debatidas as atividades de responsabilidade empresarial.

Segundo a visão dos stockholders (sócios e acionistas), "os gestores têm a atribuição formal de incrementar o retorno dos acionistas ou cotistas da empresa. Para atingir tais objetivos, os gestores deveriam atuar somente de acordo com as forças impessoais do mercado, que demandam eficiência e lucro" (MACHADO FILHO; ZYLBERSZTAJN, 2004).

De acordo com a teoria dos stockholders, os administradores devem incrementar o lucro para, assim, aumentar o valor da empresa, respeitando os direitos dos detentores de capital, sócios ou acionistas, e, desta forma, propiciando, indiretamente, o bem-estar social. Desta forma, os recursos, ao invés de destinados para ações sociais, devem ser utilizados para melhorar a eficiência da empresa.

A teoria dos stockholders mostra uma relação negativa entre responsabilidade social e desempenho financeiro e argumenta que os investimentos relacionados à responsabilidade 
social aumentam os custos e colocam empresas com tais práticas em desvantagem econômica (MCGUIRE; SUNDGREN; SCHNEEWEIS, 1988).

Enquanto a teoria dos stockholders está voltada exclusivamente para interesses de sócios e acionistas, a teoria dos stakeholders enfatiza que a alocação de recursos organizacionais e a consideração dos impactos dessa alocação devem considerar todos os interessados dentro e fora da organização.

Segundo Freeman (1984, apud WIJNBERG, 2000), existem dois tipos distintos de stakeholders: os primários e os secundários. A participação dos primários é necessária para a sobrevivência da corporação, e os stakeholders secundários não são essenciais à sobrevivência da corporação, embora as ações deles podem danificar (ou beneficiar) significativamente a corporação.

Os primários (acionistas e credores) são aqueles que possuem direitos legais sobre os recursos da empresa; e os secundários (comunidade, funcionários, consumidores, entre outros) são aqueles cujo direito sobre a sociedade não é tão claro ou é baseado em critérios de lealdade e ética (MACHADO FILHO; ZYLBERSZTAJN, 2004).

De acordo com a visão dos stakeholders, a empresa não tem um único objeto, maximizar a riqueza dos acionistas, mas múltiplos objetivos, ou seja, atender a todos os envolvidos, tanto os stakeholders primários, quanto os secundários.

Diante das duas teorias sumariamente apresentadas, e outras, muitas pesquisas foram desenvolvidas, a fim de averiguar o relacionamento da responsabilidade social, principalmente por meio de investimentos sociais, e o desempenho financeiro das empresas. A seguir, algumas pesquisas são apresentadas, sem intenção de exaurir o assunto, mas fundamentar o presente estudo.

\subsection{Relação entre investimentos socialmente responsáveis e desempenho financeiro}

Existe uma ampla literatura nacional e internacional, teórica e empírica, sobre a relação entre investimentos socialmente responsáveis e desempenho financeiro. Segundo Rezende et al. (2007, p. 6), o maior questionamento destes estudos "é se esses investimentos possuem desempenho melhor, pior ou semelhante aos outros investimentos convencionais, que não utilizam os critérios sociais, ambientais e de governança corporativa como seleção dos melhores papéis".

Uma variedade de metodologias e de comportamentos, considerados como socialmente responsáveis, é utilizada nos estudos. Por exemplo, Miles e Covin (2000) realizaram pesquisa bibliográfica, a fim de identificar evidências empíricas da relação entre performance ambiental e financeira. Neste estudo, os autores detectaram que a maioria dos trabalhos pesquisados apresentou uma relação positiva.

López, Garcia e Rodriguez (2007) examinaram o desempenho empresarial de empresas que adotaram prática de responsabilidade social. Para o estudo, foram utilizadas 110 empresas, sendo 55 empresas incluídas no Índice de Sustentabilidade Dow Jones (DJSI), e as outras 55 no Índice Global Dow Jones (DJGI), mas não inclusas no DJSI. O resultado da pesquisa apontou haver diferença no desempenho de empresas que pertencem ao DJSI e DJGI. Tal variação, nos primeiros anos em que as práticas de sustentabilidade são adotadas, apresenta-se negativa. No entanto, as estatísticas não apontaram haver uma relação positiva ao passar do tempo, sugerindo pesquisas futuras.

Bernardo et al. (2005) avaliaram a influência dos investimentos em responsabilidade social na Receita Líquida. Para tal, utilizaram o universo de 73 empresas de capital aberto que publicaram o Balanço Social de acordo com o modelo Ibase, entre os anos de 1996 e 2003. Utilizando regressão múltipla, constaram existir relação entre os indicadores internos, externos e ambientais na Receita Líquida. 
Bertagnolli, Ott e Macena (2006) buscaram determinar a influência dos investimentos sociais e ambientais no desempenho das empresas, utilizando onze indicadores sociais internos, dez indicadores sociais externos e dois indicadores ambientais como variáveis independentes e a receita líquida e o resultado operacional como variáveis dependentes. Para a realização do estudo, utilizaram análise fatorial e regressão múltipla, concluindo haver uma relação positiva entre os indicadores sociais e o desempenho econômico das empresas.

\footnotetext{
Pesquisas que tentam relacionar a performance social corporativa à performance financeira têm produzido resultados conflitantes. Os autores argumentam que estes conflitos podem ser atribuídos a razões teóricas e metodológicas como: falta de fundamentação teórica, de uma medida sistemática e adequada para performance social corporativa, de rigor metodológico, tamanho reduzido e limitações de composição das amostras e incompatibilidade entre variáveis sociais e financeiras (RUF et al., 2001 apud BARBOSA, 2007).
}

Quanto ao Índice de Sustentabilidade da Bolsa de São Paulo, Barbosa (2007) examinou o ISE, apresentando sugestões para seu aperfeiçoamento e buscando avaliá-lo como referência de sustentabilidade para gestores e investimentos, concluindo que o ISE é um referencial mais adequado para investidores do que para gestores.

Rezende et al. (2007) desenvolveram um estudo onde buscaram averiguar se o retorno do índice Bovespa de Sustentabilidade Empresarial é semelhante aos demais índices de ações. Nesse estudo, utilizaram o retorno mensal dos índices: Índice Bovespa de Sustentabilidade Empresarial (ISE), Índice Bovespa (Ibovespa), Índice Brasil (IBrx), Índice de Ações com Governança Corporativa Diferenciada (IGC), totalizando 16 observações. A estatística utilizada foi o teste $t$ de student, chegando à conclusão de que o retorno do ISE é semelhante aos retornos dos outros índices de ações.

Como no trabalho de Rezende et al. (2007) foi utilizada uma amostra muito pequena e um teste estatístico adequado para grandes amostras ou para populações que apresentam distribuição normal (teste $t$ de Student), seu estudo apresenta conclusões questionáveis. O reduzido número de observações, bem como a técnica estatística utilizada por Rezende et al. (2007), motivou a realização deste estudo com objetivo semelhante, no entanto, utilizando-se retorno diário, ou seja, ampliando as observações, e estatística adequada à amostra utilizada, atentando para todos os pressupostos dos testes estatísticos.

\section{PROCEDER METODOLÓGICO}

\subsection{Tipo de pesquisa}

Segundo a taxonomia desenvolvida por Vergara (2000), que qualifica a pesquisa quanto aos fins e quanto aos meios, o presente estudo é classificado como descritivo, uma vez que tem por objetivo averiguar se a carteira ISE apresenta desempenho, medido pela rentabilidade, igual aos das demais carteiras da BOVESPA, sem intenção alguma de explicar fenômenos.

Quanto aos meios, esta pesquisa é bibliográfica e ex post facto. A pesquisa bibliográfica, compreendendo consulta a livros, artigos de revistas especializadas e disponíveis na internet, anais de congressos, dissertações e teses sobre o tema, foi necessária para a definição conceitual deste trabalho. Considera-se ex post facto por referir-se a fatos já ocorridos, o que implica que as variáveis não puderam ser controladas ou manipuladas.

\subsection{Fundamentação teórica e hipótese}


A relação entre desempenho social e financeiro, segundo diversas pesquisas anteriores, apresentaram-se positiva, neutra e negativa. A relação negativa é consistente com o argumento da economia neoclássica, entendendo que investimentos sociais e ambientais acarretam aumento nos custos, conseqüentemente, reduzindo os lucros e, principalmente, a riqueza para os acionistas (SIMPSON; KOHERS, 2002). A mesma visão é compartilhada pela teoria dos stockolders, que prega que os administradores devem incrementar o lucro para, assim, aumentar o valor da empresa, respeitando os direitos dos shareholders, detentores do capital e que os recursos, ao invés de destinados à ações sociais, devem ser utilizados para melhorar a eficiência da empresa.

A ausência de relação entre o desempenho social e financeiro, segundo McWilliams e Siegel (2002), é fundamentada na teoria da oferta e demanda. De acordo com os autores, os investimentos sociais ocorrem de acordo com a demanda, mas mantendo sempre um equilíbrio com a maximização do lucro.

Quanto à relação positiva entre o desempenho social e financeiro, Simpson e Kohers (2002) destacam: existem conflitos entre custos explícitos da empresa, como pagamento de juros aos proprietários de títulos, e custos implícitos, como a qualidade dos produtos. A tentativa da empresa de reduzir custos implícitos por meio de ações não responsáveis pode aumentar os custos implícitos; ao passo que os custos decorrentes da responsabilidade social e ambiental são mínimos, comparados aos benefícios potenciais proporcionados à empresa. Por exemplo, o custo de prover benefícios aos funcionários pode ser muito menor, se comparado aos ganhos de produtividade resultante. Assim, investir no social e ambiental acarreta, indiretamente, melhora no desempenho financeiro.

Independente da existência de uma relação entre desempenho financeiro e social, a hipótese do mercado eficiente salienta que não é possível vencer o mercado no longo prazo. Segundo Fama (1970), mercado eficiente é um mercado aonde os preços fornecem sinais adequados para alocação de recursos, isto é, um mercado onde as empresas podem tomar decisões de produção e investimento e investidores podem escolher ativos que representam a posse dessas empresas sob a hipótese de que os preços dos ativos sempre refletirão inteiramente todas as informações relevantes disponíveis.

Para Malkiel (2003), os mercados são eficientes, quando tais mercados não permitem aos investidores obterem retornos acima da média sem incorrerem em riscos, também, acima da média. Portanto, mercado eficiente significa um mercado aonde os preços refletem todas as informações disponíveis e apresentam grande sensibilidade às novas informações. Nesse mercado, o valor de um ativo é reflexo do consenso dos participantes com relação ao seu desempenho esperado e nenhum investidor é capaz de identificar ativos com preço em desequilíbrio. Para Damodaran (2001), a eficiência do mercado é uma questão empírica.

De acordo com Malkiel (2003), os mais diretos e convincentes testes de eficiência de mercado consistem em avaliar a capacidade dos gestores profissionais de fundos de investimentos vencerem o mercado como um todo. Se os preços fossem determinados pelos investidores irracionais e sistematicamente desviassem do seu valor fundamental, bem como fosse fácil a sua previsão, então os gestores profissionais de fundos de investimentos deveriam ser capazes de vencer o mercado. No entanto, evidências sugerem o contrário, que os gestores de fundos de investimento não são capazes de bater o mercado (JENSEN, 1968; MALKIEL, 1995).

Diante do exposto, e baseado no objetivo do estudo, levanta-se a seguinte hipótese:

$\mathrm{H}_{1}$ : A rentabilidade média do Índice de Sustentabilidade Empresarial (ISE) é igual à rentabilidade média dos demais índices da BOVESPA.

\subsection{Coleta e tratamento dos dados}


Para averiguar a hipótese levantada, os dados foram coletados do próprio site da BOVESPA (www.bovespa.com.br), no período de dezembro de 2005, início da carteira ISE, a novembro de 2007, período do término do levantamento dos dados.

Os dados para a análise são as cotações diárias das carteiras da BOVESPA, a saber:

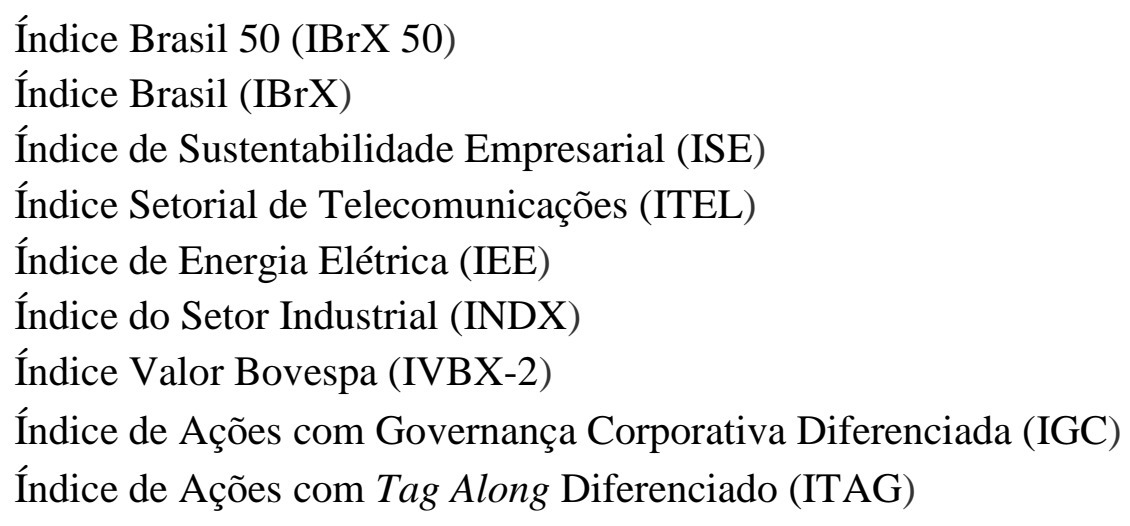

No entanto, para a comparação do desempenho das carteiras, utilizou-se o retorno diário com base na fórmula logarítmica (Equação 1), que pressupõe um regime de capitalização contínua.

Segundo Hull (1996, p.265), “os preços da ação seguem um movimento aleatório. Isso significa que mudanças proporcionais no preço da ação num curto período de tempo são normalmente distribuídas. Isso, por sua vez, implica que o preço da ação, a qualquer tempo no futuro, tem distribuição lognormal".

A escolha da fórmula logarítmica explica-se pelo fato deste método de cálculo tender a aproximar a distribuição de freqüência dos retornos calculados do logarítmico da curva normal.

$$
r=\ln \left(\frac{P_{t}}{P_{t-1}}\right)
$$

Onde:

$r$ : retorno

$P_{t}$ : cotação da carteira na data $t$

$P_{t-1}$ : cotação da carteira na data $t-1$

Vale salientar que, apesar da distribuição dos retornos calculados pela fórmula logarítmica ser simétrica, estudos, como o de Fama (1965), têm mostrado que isto não garante a normalidade de tal distribuição. Entretanto, a simetria da curva garante uma maior aproximação da normal, sendo assim mais adequada para utilizar testes paramétricos, uma vez que estes têm como pressuposto que as amostras sejam provenientes de populações normais (BROOKS, 2002).

\subsection{Técnicas estatísticas utilizadas para análise dos dados}

A fim de averiguar a igualdade entre a rentabilidade média das carteiras, utilizou-se o teste paramétrico de Análise de Variância (Anova one-way), que tem como pressupostos: (1) amostras aleatórias e independentes; (2) amostras extraídas de populações normais; e (3) as populações devem ter variâncias iguais. 
Desta forma, para garantir os resultados da Anova, são efetuados, também, os testes Kolmogorov-Smirnov, para normalidade, e Levene, para homogeneidade das variâncias.

Os dados foram, ainda, submetidos ao teste não-paramétrico Kruskal Wallis. Tal teste não exige distribuição normal e homogeneidade das variâncias, por tal motivo é considerado um teste menos robusto, mas é indispensável para garantir os resultados, em caso de violação dos pressupostos dos testes paramétricos.

\section{ANÁLISE DOS DADOS}

\subsection{Os índices da BOVESPA e a estatística descritiva}

\subsection{1 Índice de Sustentabilidade Empresarial (ISE)}

O Índice de Sustentabilidade Empresarial (ISE) foi lançado em primeiro de dezembro de 2005 pela Bolsa de Valores de São Paulo (BOVESPA), em conjunto com a Associação Brasileira das Entidades Fechadas de Previdência Complementar (ABRAPP), Associação Nacional dos Bancos de Investimento (ANBID), Associação dos Analistas e Profissionais de Investimentos do Mercado de Capitais (APIMEC), Instituto Brasileiro de Governança Corporativa (IBGC), International Finance Corporation (IFC), Instituto Ethos e Ministério do Meio Ambiente.

O objetivo do ISE é "refletir o retorno de uma carteira composta por ações de empresas com reconhecido comprometimento com a responsabilidade social e a sustentabilidade empresarial e, também, atuar como promotor das boas práticas no meio empresarial brasileiro" (ISE - METODOLOGIA COMPLETA, 2007).

O ISE foi desenvolvido com base no conceito de "Triple Bottom Line", que envolve a avaliação de elementos ambientais, sociais e econômico-financeiros de forma integrada. Além dos princípios do Triple Bottom Line, foram incluídos mais três indicadores: governança corporativa, características gerais e natureza do produto (ISE - METODOLOGIA COMPLETA, 2007).

Para fazer parte deste índice, as ações devem atender cumulativamente os seguintes critérios (ISE - METODOLOGIA COMPLETA, 2007):

a) ser uma das 150 ações com maior índice de negociação nos 12 meses anteriores à avaliação;

b) ter sido negociada em pelo menos $50 \%$ dos pregões ocorridos nos doze meses anteriores à formação da carteira;

c) atender aos critérios de sustentabilidade estabelecidos pelo Conselho do ISE.

São excluídas da carteira as ações (ISE - METODOLOGIA COMPLETA, 2007) que:

a) a empresa emissora entrar em regime de recuperação judicial ou falência;

b) no caso de oferta pública que resultar em retirada de parcelas significativas de suas ações do mercado;

c) se ocorrer evento que venha a afetar significativamente seus níveis de sustentabilidade e responsabilidade social;

d) se quando da revisão não atenda aos critérios de sustentabilidade ISE.

A primeira carteira ISE teve vigência de dezembro de 2005 a novembro de 2006 e era composta por 28 empresas de 13 setores. O setor predominante nesta carteira era o de Energia Elétrica, com 9 empresas, correspondendo a mais de 32\% da carteira (Tabela 1). Conforme o FTSE4Good (apud BARBOSA, 2007), quanto ao critério ambiental, o setor de Geração de Energia é classificado como de alto impacto sobre o meio ambiente. Assim, observa-se que a 
primeira carteira, bem com as demais apresentadas a seguir, é constituída predominantemente por empresas que apresentam um maior risco ambiental.

Seguido do setor energético, o setor Financeiro representou aproximadamente $18 \%$ da carteira e, segundo Barbosa (2007), é considerado um setor de médio impacto ambiental. O setor de Papel e Celulose, considerado como de alto impacto, representou mais de $10 \%$ da carteira, o setor de Material de Transporte aproximadamente $11 \%$ e os demais setores representaram, cada um, aproximadamente 3,5\% da carteira (Tabela 1).

A primeira renovação da carteira ISE ocorreu em 2006. Para a elaboração desta nova carteira, com vigor de dezembro de 2006 a novembro de 2007, foram excluídas seis empresas da carteira inicial e incluídas 12 novas empresas. A segunda carteira ISE era composta de 43 papéis de 34 empresas, correspondendo a 14 setores. Como já relatado, o setor de Energia Elétrica foi o mais representativo desta carteira, participando com cerca de $23 \%$ do total. $\mathrm{O}$ setor financeiro se manteve com o mesmo percentual de participação, aproximadamente $18 \%$. O setor de Siderurgia e Metalurgia que na primeira carteira representava aproximadamente $3,5 \%$ passou a ter uma representatividade de $11,7 \%$ no índice. Vale salientar que, assim como o setor energético, o setor de siderurgia e metalurgia também é considerado como de alto impacto ambiental. Os demais setores, em relação à primeira carteira, não apresentaram grandes divergências (Tabela 1).

Tabela 1 - Composição das carteiras ISE por setor

\begin{tabular}{|c|c|c|c|c|c|c|}
\hline \multirow{3}{*}{ SETOR } & \multicolumn{6}{|c|}{ CARTEIRA } \\
\hline & \multicolumn{2}{|c|}{$2005 / 2006$} & \multicolumn{2}{|c|}{$2006 / 2007$} & \multicolumn{2}{|c|}{$2007 / 2008$} \\
\hline & $\begin{array}{c}\text { Número de } \\
\text { Empresas }\end{array}$ & $\%$ & $\begin{array}{l}\text { Número de } \\
\text { Empresas }\end{array}$ & $\%$ & $\begin{array}{c}\text { Número de } \\
\text { Empresas }\end{array}$ & $\%$ \\
\hline Água e Saneamento & - & - & - & - & 1 & 3,13 \\
\hline Análise e Diagnóstico & 1 & 3,57 & 1 & 2,94 & 1 & 3,13 \\
\hline Carnes e Derivados & 1 & 3,57 & 1 & 2,94 & 2 & 6,25 \\
\hline Energia Elétrica & 9 & 32,14 & 8 & 23,53 & 11 & 34,38 \\
\hline Exploração de Rodovias & 1 & 3,57 & 1 & 2,94 & 1 & 3,13 \\
\hline Financeiro & 5 & 17,86 & 6 & 17,65 & 3 & 9,38 \\
\hline Máquinas e Equipamentos & 1 & 3,57 & & & 1 & 3,13 \\
\hline Material de Transporte & 2 & 7,14 & 2 & 5,88 & 2 & 6,25 \\
\hline Papel e Celulose & 3 & 10,71 & 3 & 8,82 & 3 & 9,38 \\
\hline $\begin{array}{l}\text { Petróleo, Gás e } \\
\text { Biocombustíveis }\end{array}$ & - & - & 1 & 2,94 & 1 & 3,13 \\
\hline Petroquímico & 1 & 3,57 & 2 & 5,88 & 2 & 6,25 \\
\hline $\begin{array}{l}\text { Produtos de Uso Pessoal e de } \\
\text { Limpeza }\end{array}$ & 1 & 3,57 & 1 & 2,94 & 1 & 3,13 \\
\hline Siderurgia e Metalurgia & 1 & 3,57 & 4 & 11,76 & 3 & 9,38 \\
\hline Construção e Transporte & 1 & 3,57 & 1 & 2,94 & - & - \\
\hline Transporte & 1 & 3,57 & 2 & 5,88 & - & - \\
\hline Consumo Cíclico & - & - & 1 & 2,94 & - & - \\
\hline $\begin{array}{r}\text { TOTAL } \\
\end{array}$ & 28 & 100 & 34 & 100 & 32 & 100 \\
\hline
\end{tabular}

Em 2007, a carteira ISE foi novamente revisada e renovada. Desta vez, com vigência de dezembro de 2007 a novembro de 2008, foi composta de 40 ações de 32 empresas, representando 13 setores da econômica. Nesta carteira, assim como nas anteriores, apresentou como setor mais representativo o de energia, com aproximadamente 34\%, seguido pelos setores Financeiro, Papel e Celulose e Siderurgia e Metalurgia, ambos com uma participação em torno de 9\%. (Quadro 1) 
Durante a vigência da carteira ISE, a cotação de fechamento máxima, em dólar, ocorreu no pregão de 31 de outubro de 2007, em valores nominais corresponde a R $\$ 1.967,31$. Quanto à menor cotação de fechamento, esta ocorreu em seis de dezembro de 2005, em valor nominal correspondeu a $\mathrm{R} \$ 1.056,36$ (Tabela 2).

Tabela 2 - Recordes anuais do ISE

\begin{tabular}{c|c|c|c|c|c|c}
\hline \hline \multirow{2}{*}{ Ano } & \multicolumn{2}{|c|}{ MAIOR FECHAMENTO DO ANO } & \multicolumn{3}{c}{ MENOR FECHAMENTO DO ANO } \\
\cline { 2 - 7 } & Nominal & US\$ & Pregão & Nominal & US\$ & Pregão \\
\hline 2005 & $1,056.36$ & 484.41 & $12 / 6 / 2005$ & $1,056.36$ & $\mathbf{4 3 1 . 0 3}$ & $12 / 6 / 2005$ \\
2006 & $1,433.42$ & 670.45 & $12 / 28 / 2006$ & $1,433.42$ & 433.61 & $12 / 28 / 2006$ \\
$2007(*)$ & $1,967.31$ & $\mathbf{1 , 1 2 8 . 0 4}$ & $10 / 31 / 2007$ & $1,967.31$ & 602.24 & $10 / 31 / 2007$ \\
\hline \hline
\end{tabular}

(*) até novembro

Mais relevante que avaliar um índice pela sua cotação é analisá-lo com base na sua rentabilidade, ou seja, quanto este índice valorizou ou desvalorizou. Efetuando a análise sob essa ótica, observa-se, conforme Tabela 3, que a rentabilidade diária média da carteira ISE, da sua vigência a novembro de 2007 , foi de 0,0012374 , com desvio padrão de 0,01568818 . A rentabilidade diária máxima foi de 0,0581523, a mínima -0,0561369 e rentabilidade diária acumulada foi de 0,610017 .

Tabela 3 - Rentabilidade diária do ISE

\begin{tabular}{l|c|r|c|c|r}
\hline \hline & Média & Desvio Padrão & Máximo & \multicolumn{1}{c|}{ Mínino } & Acumulado \\
\hline ISE & 0,0012374 & 0,01568818 & 0,0581523 & $-0,056137$ & 0,610017 \\
\hline
\end{tabular}

\subsubsection{Demais índices da Bovespa}

Além do Índice de Sustentabilidade Empresarial, foco principal deste estudo, a Bolsa de Valores de São Paulo - BOVESPA tem mais nove índices, os quais serão utilizados para fins de comparação com o ISE e apresentados sumariamente a seguir:

a) Índice BOVESPA - IBOVESPA: é considerado o índice mais importante, por retratar o comportamento dos principais papéis negociados na BOVESPA, manter a integridade de sua série histórica e não ter sofrido modificações metodológicas desde a sua implantação em 1968 (BOVESPA, 2007).

b) Índice de Ações com Governança Corporativa Diferenciada - IGC: este índice tem por objetivo medir o desempenho de uma carteira teórica composta por ações de empresas que apresentam bons níveis de governança corporativa (BOVESPA, 2007).

c) IBrX-50: é composto pelos 50 papéis mais negociados na BOVESPA, em termos de liquidez, e mede o retorno total de uma carteira teórica ponderado pelo valor de mercado das ações da carteira disponíveis à negociação (BOVESPA, 2007).

d) Índice Brasil - IBrX: tem as mesma características do IBrX-50, ou seja, mede o retorno de uma carteira teórica, sendo as ações ponderadas na carteira pelo seu respectivo número de ações disponíveis à negociação no mercado. Difere da $\mathrm{IBrX}$ por ser composta por 100 papeis mais líquidos da BOVESPA, ao passo que a IBrX é composta por 50 ações (BOVESPA, 2007).

e) Índice Valor Bovespa $2^{\mathrm{a}}$ Linha - IVBX-2: tem por objetivo mensurar o retorno de carteira hipotética composta por 50 papéis emitidos por empresas de excelente conceito junto aos investidores (BOVESPA, 2007).

f) Índice de Ações com Tag Along - ITAG: é um índice que mede o desempenho de uma carteira teórica composta por ações de empresas que ofereçam melhores 
condições aos acionistas minoritários (BOVESPA, 2007).

g) Índice Setorial de Telecomunicações - ITEL: é um índice representativo de um setor de telecomunicações composto pelas empresas mais representativas do setor, incluindo telefonia fixa e celular, cujos papéis são ponderados pelo valor de mercado das ações em circulação - Free Float (BOVESPA, 2007).

h) Índice de Energia Elétrica - IEE: tem por objetivo medir o desempenho do setor de energia elétrica, sendo composto pelas empresas abertas mais significativas desse segmento (BOVESPA, 2007).

i) Índice do Setor Industrial - INDX: este índice ter por objetivo medir o retorno de uma carteira teórica composta pelas ações mais representativas da indústria, que são selecionadas entre as mais líquidas, e são ponderadas na carteira pelo valor de mercado das ações disponíveis à negociação (BOVESPA, 2007).

Com base na Tabela 4, é possível observar que o índice IBrX apresentou a maior rentabilidade média e acumulada. A rentabilidade máxima do período em estudo foi do IEE e a rentabilidade mínima do ITEL.

Tabela 4 - Estatística descritiva da rentabilidade dos índices BOVESPA

\begin{tabular}{l|c|r|r|r|r}
\hline \hline Indices & Média & Desvio Padrão & Máximo & \multicolumn{1}{c}{ Mínino } & Acumulado \\
\hline ISE & 0,001237 & 0,015688 & 0,058152 & $-0,056137$ & 0,610017 \\
IBOVESPA & 0,001335 & 0,016027 & 0,048447 & $-0,068566$ & 0,658393 \\
IGC & 0,001374 & 0,015289 & 0,050773 & $-0,059568$ & 0,677597 \\
IBrX 50 & 0,001515 & 0,015436 & 0,048740 & $-0,063367$ & 0,747114 \\
IBrX & $\mathbf{0 , 0 0 1 5 4 8}$ & 0,014915 & 0,046357 & $-0,062413$ & $\mathbf{0 , 7 6 3 0 7 0}$ \\
IVBX-2 & 0,001074 & 0,014199 & 0,045682 & $-0,057551$ & 0,529387 \\
ITAG & 0,001325 & 0,015568 & 0,053621 & $-0,054621$ & 0,652990 \\
ITEL & 0,000631 & 0,016945 & 0,055591 & $\mathbf{- 0 , 0 7 4 2 6 7}$ & 0,311005 \\
IEE & 0,001145 & 0,015020 & $\mathbf{0 , 0 5 8 9 2 7}$ & $-0,051053$ & 0,564338 \\
INDX & 0,001467 & 0,013954 & 0,044464 & $-0,058213$ & 0,723026 \\
\hline
\end{tabular}

\subsection{Análise da Hipótese}

O objetivo principal do estudo é averiguar se a rentabilidade média do ISE é igual a dos demais índices da BOVESPA. Para atender ao objetivo proposto, poderia ser realizado o Teste $t$ de Student para comparar o ISE com cada um dos índices. No entanto, foi preferível utilizar a Anova one-way e, desta forma, comparar também todos os índices simultaneamente entre si.

Como um dos pressupostos para a utilização da Anova é que a distribuição da população, proveniente da variável em estudo, apresente distribuição normal, utilizou-se o teste Kolmogorov-Smirnov para averiguar a normalidade, conforme Tabela 5.

Tabela 5 - Teste de Kolmogorov-Smirnov para normalidade

\begin{tabular}{l|c|r|r}
\hline \hline \multicolumn{1}{c|}{ Indice } & $\mathrm{N}$ & Estatística & $p$-value \\
\hline ISE & 493 & 0.053094 & 0.002058 \\
IBOVESPA & 493 & 0.055667 & 0.000932 \\
IGC & 493 & 0.052765 & 0.002270 \\
IBrX50 & 493 & 0.054572 & 0.001312 \\
IBrX & 493 & 0.055511 & 0.000979 \\
IVBX2 & 493 & 0.070079 & 0.000005 \\
ITAG & 493 & 0.056578 & 0.000696 \\
ITEL & 493 & 0.043228 & 0.028152 \\
IEE & 493 & 0.046100 & 0.014086 \\
INDX & 493 & 0.053361 & 0.001899 \\
\hline
\end{tabular}


A partir dos resultados do teste de Kolmogorov-Smirnov, percebe-se que a rentabilidade dos índices não apresenta distribuição normal, ao nível de 5\%, uma vez que todos os índices apresentam $p$-value menor que o nível de significância $(0,05)$.

Embora os índices não tenham apresentado uma distribuição normal, baseado no Teorema do Limite Central, que esclarece que mesmo no caso de uma distribuição nãonormal, a distribuição das médias amostrais será aproximadamente normal, desde que a amostra seja grande (BROOKS, 2002) e considerando grande a amostra de 493 observações efetuou-se a Anova com as seguintes hipóteses:

$\mathrm{H}_{0}$ : Todos os índices apresentam rentabilidade igual

$\mathrm{H}_{1}$ : Pelos menos um índice apresenta rentabilidade diferente dos demais

Levantadas as hipóteses, segue a estatística teste da Anova one-way (Tabela 6).

Tabela 6 - Estatísticas teste

\begin{tabular}{l|c|c}
\hline \hline & Estatística & p-valor \\
\hline Anova one-way & 0,1531 & 0,9980 \\
Teste Levene & 2,3037 & 0,0140 \\
Kruskal Wallis & 1,6307 & 0,9961 \\
\hline \hline
\end{tabular}

Com base na Anova one-way, Tabela 5, observa-se que todos os índices apresentam rentabilidade igual, considerando um nível de significância de 5\%, pois o $p$-value é maior que 0,05. Para validar o resultado encontrado, testou-se a homogeneidade das variâncias da amostra, por meio do teste Levene, apresentado na Tabela 5.

De acordo com a estatística de Levene, conclui-se que as variâncias não são homogêneas, ao nível de 5\%, já que o p-value apresentou-se menor que 0,05. Logo, o resultado da Anova não pode ser utilizado para concluir sobre a igualdade da rentabilidade dos índices.

Para responder ao proposto, recorreu-se ao teste não-paramétrico de Kruskal Wallis. Tal teste não exige normalidade e homogeneidade, por tal motivo é considerado um teste menos robusto, mas é indispensável para garantir os resultados, em caso de violação dos pressupostos dos testes paramétricos, como o evidenciado nesse artigo.

Baseado no teste não-paramétrico de Kruskal Wallis, apresentado na Tabela 5, é possível concluir que os índices em estudo não apresentam diferenças em seus retornos diários ao nível de significância de 0,05 ou 0,01. O resultado apresentado corrobora com o estudo desenvolvido por Rezende et al. (2007), que apontou que o Índice de Sustentabilidade Empresarial não possui melhor retorno que outros índices de ações.

Embora tenha havido todo o cuidado quanto à utilização dos testes estatísticos, o resultado apresentado não pode levar a conclusão de que empresas que adotam práticas de responsabilidade apresentam desempenho semelhante à empresas que não fazem usos destas práticas, mas simplesmente que o Índices de Sustentabilidade Empresarial da Bolsa de São Paulo, no período estudado, apresentou retorno médio semelhante a outros índices.

A justificativa para este retorno médio semelhante pode residir no fato de que uma parcela significativa de empresas que compõe o ISE faz parte simultaneamente de outros indicadores, sugerindo pesquisas futuras que considerem esse fato.

\section{CONCLUSÃO}

A presente pesquisa teve por objetivo averiguar se a rentabilidade média do Índice de Sustentabilidade Empresarial (ISE) é estatisticamente igual à rentabilidade dos demais índices da BOVESPA, dentro do período de dezembro de 2005 a novembro 2007. 
Para atingir o objetivo proposto, fez-se usos de testes paramétrico e não paramétrico, concluindo não haver diferença significativa entre os índices: Índice Brasil 50 (IBrX 50), Índice Brasil (IBrX), Índice de Sustentabilidade Empresarial (ISE), Índice Setorial de Telecomunicações (ITEL), Índice de Energia Elétrica (IEE), Índice do Setor Industrial (INDX), Índice Valor Bovespa (IVBX-2), Índice de Ações com Governança Corporativa Diferenciada (IGC), Índice de Ações com Tag Along Diferenciado (ITAG).

O resultado apresentado não pode levar à conclusão de que investimentos socialmente responsáveis apresentam o mesmo retorno de investimentos que não adotam a mesma postura, mas que o retorno médio dos índices é semelhante, uma vez que um número relevante de empresas compõe simultaneamente mais de um índice.

Devido ao fato de empresas comporem concomitantemente vários índices, é sugerido pesquisas futuras que tratem dessa questão considerando a participação de uma mesma empresa em diversos índices, bem com estudos utilizando metodologias diferentes que possam corroborar com os achados do presente.

\section{REFERÊNCIAS}

ASHLEY, P. A.; COUTINHO, R. B. G. O; TOMEI, P. A. Responsabilidade social corporativa e cidadania empresarial: uma analise conceitual comparativa. . In: ENANPAD, 24.,2000. Anais... Rio de Janeiro: ANPAD, 2000.

BARBOSA, P. R. A. Índice de sustentabilidade empresarial da bolsa de valores de São Paulo (ISE-BOVESPA): exame da adequação como referência para aperfeiçoamento da gestão sustentável das empresas e para formação de carteiras de investimento orientadas por princípios de sustentabilidade corporativa. 2007. Dissertação (Mestrado em Administração) Universidade Federal do Rio de Janeiro, Instituto COPPEAD de Administração, 2007.

BELAL, A. R. A study of corporate social disclosures in Bangladesh. Managerial Auditing Journal, v. 16, n. 5, 2001.

BERNARDO, D. C. R. et al. Responsabilidade social empresarial: uma análise dos Balanços Sociais das Sociedades Anônimas de Capital Aberto. In: ENANPAD, 29., 2005, Brasília. Anais... Rio de Janeiro: ANPAD, 2005.

BERTAGNOLli, D. D. O.; OTT, E.; DAMACENA, C. Estudo sobre a influência dos investimentos sociais e ambientais no desempenho econômico das empresas. In: CONGRESSO USP, 6., 2006, São Paulo. Anais... São Paulo, FEA/USP, 2006.

BOLSA DE VALORES DE SÃO PAULO (BOVESPA). Mercado: Ações - Índices. 2007. Disponível em: <http://bovespa.com.br>. Acesso em: 5 dez. 2007.

BROOKS, C. Introductory econometrics for finance. Cambridge: Cambridge University Press, 2002.

BYRCH, C. et al. Sustainable "what"? A cognitive approach to understanding sustainable development. Qualitative Research in Accounting \& Management, v. 4, n. 1, 2007. http://dx.doi.org/10.1108/11766090710732497

DAMODARAN, A. Corporate finance: theory and practice. 2 ed. New York: Wiley Series in Finance, 2001.

FAMA, E. The behavior of stock prices. Journal of Business, v. 47, 1965.

FAMA, E. Efficient markets: a review of theory and empirical work. Journal of Finance, v. 25, n. 2, p. 383-417, 1970. http://dx.doi.org/10.2307/2325486 
HULL, J. Introdução aos mercados futuros e de opções. 2. ed. São Paulo: Bolsa de mercados \& Futuros e Cultura Editores Associados, 1996.

INSTITUTO ETHOS. Guia de elaboração do Balanço Social. Disponível em: <http://ethos.org.br>. Acesso em: 5 dez. 2007.

JENSEN, M. The performance of mutual fund in the period 1945-1964. Journal of Finace, v. 23, p. 389-416, 1968. http://dx.doi.org/10.2307/2325404

LÓPEZ, M. V. et al. Sustainable Development and Corporate Performance: A Study Based on the Dow Jones Sustainability Index. Journal of Business Ethics, Springer 2007. http://dx.doi.org/10.1007/s10551-006-9253-8

MACHADO FILHO, C. A. P.; ZYLBERSZTAJN, D.. A empresa socialmente responsável: o debate e as implicações. RAUSP. Revista de Administração, v. 39, n. 3, p.242-254, jul./set. 2004.

MALKIEL, B. G. The efficient markets hypothesis and its critics. Journal of Economic Perspectives, v. 17, n. 1, p. 59-82, 2003. http://dx.doi.org/10.1257/089533003321164958

MALKIEL, B. G. Returns from investing in equity mutual funds. Journal of Finance, v.50, n.2, p. 549-572, 1995. http://dx.doi.org/10.2307/2329419

MASUlO, D. G. Condicionantes da divulgação de informações sobre responsabilidade ambiental nas grandes empresas brasileiras de capital aberto: internacionalização e setor de atuação. 2004. Dissertação (Mestrado em Administração) - Universidade Federal do Rio de Janeiro, Instituto COPPEAD de Administração, 2004.

MCGUIRE, J. B.; SUNDGREN, A.; SCHNEEWEIS, T. Corporate social responsibility and financial performance. Academy of Management Journal. v. 31, n. 4, 1988. http://dx.doi.org/10.2307/256342

MACWILLIAMS, A.; SIEGEL, D. Corporate social responsibility: a theory of the firm perspective. Academy of Management Review, v. 26, 2001.

MILES, M. P.; COVIN, J. G. Environmental marketing: a source for reputational competitive and financial advantage. Journal of Business Ethics, v. 23, 2000. http://dx.doi.org/10.1023/A:1006214509281

NORMAN, W.; MACDONALD, C. Getting to the bottom of "Triple Bottom Line". Business Ethics Quarterly. March 2003.

REZENDE, I. A. C. et al. Um estudo sobre o desempenho financeiro do Índice BOVESPA de Sustentabilidade Empresarial. In: ENANPAD, 31., 2007, Rio de Janeiro. Anais... Rio de Janeiro, ANPAD, 2007.

SIMPSON, W. G.; KOHERS, T.; The link between corporate social and financial performance: evidence from the banking industry. Journal of Business Ethics, v. 35, n. 2, jan. 2002. http://dx.doi.org/10.1023/A:1013082525900

VERGARA, S. C. Projetos e relatórios de pesquisa em administração. 3. ed. São Paulo: Atlas, 2000.

WIJINBERG, N. M. Normative stakeholder theory and Aristotle: the link between ethics and politics. Journal of Business Ethics, v. 25, Jun. 2000. http://dx.doi.org/10.1023/A:1006086226794 